\title{
An Investigation on Academic Writing Problems Encountered by Undergraduate Students of Shaheed Benazir Bhutto University, Sanghar Campus
}

\author{
Arham Arif \\ BS English Linguistics at Shaheed Benazir Bhutto University, Sanghar Campus, Pakistan \\ Syed Hyder Raza Shah \\ Lecturer English at Shaheed Benazir Bhutto University, Sanghar Campus, Pakistan \\ Fakhra \\ BS English Linguistics at Shaheed Benazir Bhutto University, Sanghar Campus, Pakistan \\ Arshad Ali \\ BS English Linguistics at Shaheed Benazir Bhutto University, Sanghar Campus, Pakistan
}

\begin{abstract}
The aim of this research is to investigate the academic writing problems encountered by undergraduate students of Shaheed Benazir Bhutto University, Sanghar Campus and to suggest the effective strategies to cope up these problems. Qualitative method was used to collect the data in which 12 students and 3 teachers were selected for semi structured interviews. The conducted interviews were thematically analyzed. Findings of this research revealed that the lack of logical thinking, intended delivering expressions and repetition of ideas in academic writing are the major problems of student. Teachers recommended some strategies that writing short sentences, using simple vocabulary, mind mapping, influential language and cohesive devices can help students to improve academic writing. The study suggested that critical reading and frequent feedback from teachers will help students to overcome the problems of academic writing.
\end{abstract}

Keywords: Academic writing, logical thinking, undergraduate students, and vocabulary.

DOI: $10.7176 / \mathrm{JLLL} / 68-03$

Publication date:May $31^{\text {st }} 2020$

\section{Introduction}

These days, English is significant in every single instructive action. Students mostly prefer the universities where English is the medium of instruction in teaching. According to (Adams, K. H., \& Keene, M, 2000) through English student can easily deal with the academic needs and can play a productive role in their domains and context. The most important and challenging aspect for university students is academic writing. Specifically, this is the case of L2 or Foreign language learner. Academic writing plays a vital role in EFL learning. According to (Thaiss, 2006) academic writing is a process that intends to fulfill the aim of education. It plays an important role to socialize the students to express the motive and domain in universities. A quality of academic writing is to concentrate on creating new ideas, organize them and perform in acceptable manner and write it again after getting the views of readers. Second language learners feel difficulties in learning academic writing because it is difficult to utilize non- native language precisely and accurately. According to (Ismail, 2011) English writing facilitate students to think in critical way and inspires them to learn the various aspects of academic writing, e.g. using great vocabulary and powerful expressions. Academic writing has various elements, like self-expression and essential reduction. Academic writing has different parts such as, using appropriate conjunctions, paraphrasing, and impressive style of word structures. There are also some factors which involves the use of some steps, that students should be follow before writing. Such as: summarizing, understanding the paragraphs, excluding unnecessary words, changing long sentences by breaking them and express some meaning by using different words (synonyms of that words). (Johns, 2008) said that novice writers permit themselves to achieve their writing task after safe examination by using various rhetorical and linguistic options to accomplish important tasks.

Academic capacities are a basic portion of communication for the understudies all through their scholastic life since it grants them to arrange their assumptions and considerations obviously and moreover to pass on significance through well-created content. Academic writing is vital but still very difficult skill for learners to learn. (Negari, 2011) Students are facing various problems in different areas; from correct spelling to evolve an argument in his essay. According to Zamel, V. (1983) during the activities of academic writing learners can get affective ideas for accurate language use in writing process. Thus, students must be familiar with the kinds of academic writing, such as narrative, illustrative, descriptive approaches and strategies by applying critical thoughts, paraphrasing writing in their own wording. The academic writing challenges amid students can be connected to 
the writing discipline. Such as communication, understanding and management discipline. In so many cases, some students may misunderstand and face hurdles in understanding the academic writing instructions are given by nonnative English speakers. Further, instructions for academic writing are not very much clear for their position to be executed. In other words, (Fawwaz, A.-H., \& Ahmed, A., 2007) distinguished a few issues related to students' considering in overseeing a few tests to move forward their scholarly writings such as the utilize of cohesion viewpoints, frail association among the words, and the need in creating certain sorts of disciplines in scholastic composing.

\subsection{Significance of the study}

In the process of learning English, academic writing considered as essential part. By knowing the difficulties in academic writing and student's needs, there will be a reasonable image of the best and productive course books to be received in their respective projects and programs. Obviously, lecturers put forth a valiant effort and apply a great deal of time and endeavor to improve their students writing. Undesirably, in most of the cases the concluding production of writing is not worthy as acknowledged to be. That is the reason most of educators see writing the most troublesome skills as instruct (Al Murshidi, (2014). The consequences of present investigation produce essential bits of knowledge that could add to increasingly advantageous direction for the teachers. The discoveries can be similarly important in term of proposing some potential responses for the difficulties that undergraduate students experienced while academic writing.

\subsection{Problem Statement}

Academic writing is a challenging task for ESL learners because all the ESL learners do not have command over the English grammar, vocabulary or other areas of writing. There are a lot of problems which they face and which become the hurdles in their fair academic writing, which directly or indirectly affect their grades in competitive exams.

\subsection{Aim and Objectives}

The aim of this research is to investigate the academic writing problems encountered by undergraduate students at SBBU, Sanghar Campus, and to suggest the effective strategies to cope up academic writing problems.

1. To investigate the academic writing problems encountered by undergraduate students.

2. To find out the effective strategies to cope up academic writing problems.

\subsection{Research Questions}

1. What are the academic writing problems encountered by undergraduate students?

2. What are the effective strategies to cope up academic writing problems?

\section{Review of related literature}

(kareem, 2013) distinguished academic writing as the development and manufacture of such techniques taught in universities as like producing and systemizing the thoughts of students and their vocabulary development, critical thinking and grammatical syntax (2013, p.1553).

Al-Badi explains the writing as a difficult procedure. Al-Fadda (2012, p. 123) describes that writing academically in English at the proficient level is a challenging task for the most of the native speakers too. In acquiring any foreign language (FL), the academic writing plays significant role. It comprises such crucial elements like; self-expressing and critical thinking. Also, the techniques which include the summarizing and rewording cannot be neglected while writing academically (kareem, 2013). It is an acceptable truth especially for those who are working on research articles as the scholars. They have to use the others' works into utilizing that into their own voice. Writing is learnt from two differ and theoretical perspectives: socio cultural and cognitive. The cognitive viewpoint is the goal oriented and it focuses on the process of writing and repeating while the socio cultural viewpoint is context oriented and it focuses on the production of writing for a specific purpose (Lee, 2005).

\subsection{Previous studies}

(Al-Mukdad, 2019) had an examination on Investigating English Academic Writing Problems Encountered by Arab International University Students. He used quantitative method for conducting the research, the number of participants was 50 students from different fields at Arab International University (AIU), and the subjects were given the survey to fill. The study resulted that the students are not well aware about the differences of English like; general English and Academic English, it happens because of the lack of background about academic writing. Another major problem was declared that it happens because of various linguistic rudiments.

(Al Badi, 2015) conducted a research on the difficulties of academic writing for ESL learners. He used mixed method for conducting the research. He involved 20 postgraduate students; those students were from different four nationalities studying at university at Australia. He distributed 2 types of questionnaires among the participants. 
$1^{\text {st }}$ questionnaire contained closed questions while the $2^{\text {nd }}$ questionnaire contained the material to support the data gathered by $1^{\text {st }}$ questionnaire and it was mostly open ended questionnaire. The findings of the research revealed that their previous educational background affects their academic writings. The most ordinary mistakes are like; coherence and cohesion fault and the proper usage of language. The study also revealed that students mix their own ideas in others' ideas lead their academic writings to be poor.

(Pineteh, 2013) had study on the academic writing challenges of undergraduate students at South Africa. He used qualitative method for doing this research, in which he involved 20 participants of $1^{\text {st }}$ and $2^{\text {nd }}$ year, 12 of them were male participants while rest of them were male participants. He used interview as the tool for collecting data. All the participants were interviewed and the questions were adopted from different research papers, the interview consisted of 20-30 minutes. The study resulted that the literacy backgrounds, the linguistic background, attitudes of students towards academic writing.

(Al-Khairy, 2013) had an investigation on academic writing problems of Saudi English major undergraduates. He used quantitative method in which close ended questionnaire were given to the students and the data was analyzed by SPSS and was completed with descriptive analysis. The findings of his research show that undergraduate students commit a lot of mistakes in academic writing because they faced problems in coherence and cohesion of sentences.

(Khan, 2011) directed an investigation on academic writing problems faced by undergraduate students of Saudi university. He used quantitative method and findings of his research reveals that students faced problems in grammar, vocabulary, spelling errors, incorrect use of prefixes and suffixes.

(Al Fadda, 2012) led an exploration on challenges in academic composition: from the point of view of King Saud college postgraduate understudies. He used quantitative method for conducting the research, in which he involved 50 participants. The participants were the postgraduate students of academic year 2009-10. He distributed the questionnaire among the participants and analyzed the data by descriptive approach. The findings of this research indicated that students whose English is the Second language, face different challenges and stress while writing academically, such as the complexity to distinguish the written English and spoken English, recognizing the techniques and abilities which are essential for a successful writing, evading from epidemic vocabulary and designing the outline before drafting.

(Al Mubarak, 2017) had conducted research on problems of academic writing faced by undergraduate students of Al Imam Ali Mahdi University Sweden. He used quantitative method to collect the data and the data was collected from 15 students of final year, belongs to BA department. Findings of his research reveal that, $70 \%$ students faced problems in punctuations and prepositions. Remaining students faced difficulties in consistency in sentences.

(Bitchener, J., \& Basturkmen, H., 2006) investigated an investigation on the topic Second language (L2) postgraduate students' perceptions of difficulties faced in writing the discussion of their thesis in New Zealand. They adopted the qualitative method for conducting the research. They adopted the interviews for collecting the data, in which he involved the teachers, supervisors of Second language as well as the learners of the second language. The findings of the study revealed that in the comparison of supervisors, the students have more issues and face more issues while writing discussion section of their thesis. Additionally, both students and supervisors have bounded knowledge of the features and causes for the difficulties while writing. Their perceptions for writing problems of the students differ from each other.

(Al-Khasawneh, 2010) directed an examination on the theme composing for academic purposes: issues looked By Arab postgraduate understudies of the school of Business, University. He used qualitative method for conducting the research. And the tools he adopted were the semi-structured interviews. 10 Arab and post-graduate students of the business programs as the informants were involved which were interviewed. The results of the study revealed that there are different problems and issues which are faced by the students, those problems include; problem in organizing the ideas means the lack of the awareness of cohesion and coherence, less proficiency on grammar rules, spelling, vocabulary register and referencing like problems.

\section{Research Methodology}

In the present study, researcher has used the qualitative method to conduct the research for knowing the deepness of thoughts. The subjective research is developing request of scientists of sociologies (Dornyei, 2007). Research in subjective model talks about the systems of gathering information in open-finished poll that investigate interpreted accounts in subjective substance. This study used semi structured interview in which one on one interviews were conducted from 12 students and 3 teachers. The questions for interview were taken from the main two research questions, and interviews were conducted from Shaheed Benazir Bhutto university Sanghar campus. The thematic analyses were used to analyze the data. Researcher has chosen this thematic analysis "because it can help the researcher to examine and analyze the data" (Braun, V. and Clarke, V., 2006). Qualitative method was welcomed by the researchers of applied linguistics in mid 1990s. Conversely, in applied linguistics, qualitative research offers observations, interviews, and authentic documents of communication behavior (p.193). This 
analysis is very helpful for getting rich and accurate collection of data.

\section{Findings of Q1}

Findings of this study revealed that lack of logical thinking, delivering intended expressions, repetition of ideas, lack of understanding and grammatical errors are the major academic writing problems encountered by undergraduate students.

\subsection{Lack of logical thinking}

Most of participants face these problems in academic writing because they don't have power of comprehension, they do not read the books which become hurdle in writing logical ideas, and Because Illogical ideas can never make a successful piece of text in writing process. Logical thinking does not come by itself, but through the comprehension of books, intellect and experience.

\subsubsection{Delivering intended expressions}

This is most common factor among the students that they mostly remain fail to deliver their exact intended expressions while writing any idea. The students think that they have encountered the expression exactly as they have intended. Consequently, when reader read the text, do not understand the actual meaning of that writing.

\subsubsection{Repetition of ideas}

Most of the participants were of the view that they faced this difficulty in academic writing because English is not their mother tongue. So they have not proper command over vocabulary and the whole language. They repeat their ideas and words again and again, which abolish their writing.

\subsubsection{Lack of understanding}

Participants were of the view that, they cannot understand the given topic to write. When they start writing, they do not have enough understanding of their ideas related to topic. Arrangement of ideas is another big issue which they faced while writing. Student are not able to understand that which ideas they have to write specifically and which they should write generally.

\subsubsection{Grammatical Errors}

For some students the major issue is the difference between their native language and target language. They are totally opposite to each other and become reason of grammatical errors. Mostly students tried to translate their native language into target language, so in this case they do not apprehend how to convert vocabulary, prepositions and structure of sentences from their native language to target language. It leads them to grammatical errors. Students are not expertise on punctuation. They do not use it correctly which totally changes the meaning of sentences.

\subsection{Findings of Q2}

To deal with problems in academic writing Teachers recommended some strategies that writing short sentences, using simple vocabulary, mind mapping, influential language and cohesive devices can help students to improve academic writing.

\subsubsection{Strategies}

\subsubsection{Mind Mapping}

Teachers suggested that in academic writing mind mapping plays a vital role because it all about that how individual become creative in academic writing while using mind map. Mind mapping is a graphical tool that helps to structure information and helps you examine, recall, synthesize, understand and develop new ideas better. It enhances the cognitive ability in relation to the number of ideas produced and strengthens the focus on writing. Mind mapping can be utilized in any action where thought, arranging, review, or inventiveness is included, as indicated by (Buzan, 1989). In the context of related ideas with images and keywords, a mind map allows individual to record a wealth of information.

\subsubsection{Cohesive devices}

Cohesion refers to producing a coherent and fluid text by using transition terms, including reference words or conjunctions. There are total six types of transition words which help to accomplish text or document cohesion.

I. In descriptive writing spatial order words are used to indicate spatial relationship. Such as: next to, above, inside, outside, below and beside.

II. In writing stories time order words are used to indicate systematic arrangements. Such as: first, after, next, when, then, during, while, as, later, meanwhile and finally.

III. In expository writing numerical order words are used to indicate priority order. Such as: also, first, finally, in addition, second, less and more importantly.

IV. In expository writing effect/cause word orders are also used to indicate connecting relationships. Such as: since, so, for, consequently, hence, thus and as a result.

V. In expository writing, comparison/contrast words orders are also used to indicate differences and similarities. For instance: (for comparison) additionally, also, as though, as if, similarly, like and just as; 
and (for contrast) on the other hand, in spite of, but, yet, conversely, in contrast, however, nevertheless, rather and instead.

VI. In descriptive reports specific/general word orders are used to indicate more explicit explanation on a notion. Namely: such as, like, for instance, for example, in other words, indeed and in fact.

Conjunctions are used to linking the sentences (besides linking different parts of the same sentences) and it might have subsequent functions: result, addition, opposition, reason, time and example. Pronouns, objective pronouns, possessive pronouns and demonstrative pronouns are the examples of reference words. Repetition of phrases and keywords, using paraphrasing and synonyms also help to build a cohesive message or text.

\subsubsection{Writing short sentences}

The sentences in academic writing should be used short. Complex and complex compound sentences should be avoided in academic writing, which will not lead the reader towards getting bore and also save time.

\subsubsection{Using simple vocabulary}

In academic writing vocabulary should be used general. The selection of the words should be the according to the situation/scenario of the passage. The vocabulary should not be as the flowery language, it must be simple and easy words. It helps students to convey their ideas easily and effectively.

\subsubsection{Influential language}

Influential language in academic writing empowers ideas and makes the writing effective. The language which should be used must be such influence over the reader. The language also should be regional but the reader should be influenced by the usage of the language.

\section{Discussion}

Al-Badi (2015) conducted a research on the difficulties of academic writing for ESL learners. He used mixed method for conducting the research. He involved 20 postgraduate students; those students were from different four nationalities studying at university at Australia. He distributed 2 types of questionnaires among the participants. $1^{\text {st }}$ questionnaire contained closed questions while the $2^{\text {nd }}$ questionnaire contained the material to support the data gathered by $1^{\text {st }}$ questionnaire and it was mostly open ended questionnaire. The findings of the research revealed that their previous educational background affects their academic writings. The most ordinary mistakes are like; coherence and cohesion fault and the proper usage of language. The study also revealed that students mix their own ideas in others' ideas lead their academic writings to be poor.

Al-Mukdad (2019) had an investigation on Investigating English Academic Writing Problems Encountered by Arab International University Students. He used quantitative method for conducting the research, the number of participants was 50 students from different fields at Arab International University (AIU) and the subjects were given the survey to fill. The study resulted that the students are not well aware about the differences of English like; general English and Academic English, it happens because of the lack of background about academic writing. Another major problem was declared that it happens because of various linguistic rudiments.

By intending the finding of above authors, the findings of this present study revealed that lack of logical thinking, delivering intended expressions, repetition of ideas, lack of understanding and grammatical errors are the major problems faced by undergraduate students of Shaheed Benazir Bhutto University Sanghar Campus. This study also recommends some strategies to cope up academic writing problems. The strategies recommend by this study, will be convenient for the future learners.

\section{Conclusion}

Academic writing is a process that intends to fulfill the aim of education. The aim of this research is to investigate the academic writing problems encountered by undergraduate students at SBBU, Sanghar Campus, and to suggest the effective strategies to cope up academic writing problems. Qualitative method was used to collect the data in which semi structured interview was conducted. Data was analyzed by thematic analysis. Findings of this research revealed that lack of logical thinking, delivering intended expressions, grammatical errors and repetition of ideas in academic writing is the major problems of student. This study recommend some strategies that using simple vocabulary, mind mapping, influential language and using short sentences can help students to cope up academic writing problems. This study suggests that critical reading and frequent feedback from teachers will help students to overcome academic writing problems.

\section{Reference}

Adams, K. H., \& Keene, M. (2000). Research and writing across the disciplines. New York: McGraw Hill. Al Badi, I. (2015). Academic writing difficulties of ESL learners. In the WEI International Academic Conference Proceedings. Spain, Barcelona.

Al Fadda, H. (2012). Difficulties in academic writing: from the perspective of King Saud University postgraduate students. English Language Teaching, . 5 (3). 123-130.

Al Mubarak, A. A. (2017). An investigation of academic writing problems level faced by undergraduate students 
at Al Imam Al Mahdi University - Sudan. . Journal of English Education, , 5(2), 175-188.

Al Murshidi, G. (2014). UAE university male students' interests impact on reading and writing performance and improvement. English Language Teaching, . 7(9), 57-63.

Al-Khairy, M. A. (2013). Saudi English-major undergraduates' academic writing problems: A Taif university perspective. English Language Teaching, . 6(6).

Al-Khasawneh, F. M. (2010). Writing for academic purposes: Problems faced by Arab postgraduate students of the college of business. . UUM. ESP World, , 28(9), 1-23.

Al-Mukdad, S. (2019). Investigating English Academic Writing Problems Encountered by Arab International University Students. Theory and Practice in Language Studies, 300-306.

Bitchener, J., \& Basturkmen, H. (2006). Perceptions of the difficulties of postgraduate L2 thesis students writing the discussion section. . Journal of English for Academic Purposes, , 5, 4-18 .

Braun, V. and Clarke, V. (2006). Using thematic analysis in psychology. Qualitative Research in Psychology . 3 (2). pp. 77-101. ISSN 1478-0887.

Buzan, T. (1989). Use Both Sides of Your Brain, 3rd ed., Plenum, NewYork, NY. .

Fawwaz, A.-H., \& Ahmed, A. (2007). Discourse problems in argumentative writing. Language \& Linguistics, . 13(3).

Imran Mahmud, (2011). Mind Map For Academic Writing: A Tool To Facilitate University Level Students. International Journal of Educational Science and Research Vol.1, Issue 1, 21- 30 .

Ismail, S. A. (2011). Exploring students' perceptions of ESL writing. English Language Teaching,. 4(2), 73.

Johns, A. M. (2008). Genre awareness for the novice academic student: An ongoing quest. Language Teaching. $41(2), 237$.

kareem, A. (2013). An investigation study of academic writing problems faced by Arab postgraduate Students at Universiti Teknologi Malaysia (UTM). . Theory and Practice in Language Studies, , 3 (9), 1552-1557.

Khan, I. A. (2011). Learning difficulties in English: Diagnosis and pedagogy in Saudi Arabia. Educational Research, . 2(7), 1248-1257.

Lee, N. (2005). Understanding students' perceptions of difficulty with academic writing for teacher development: A case study of the University of Tokyo writing program . 14, 1-11.

Negari, G. M. (2011). A study on strategy instruction and EFL learners' writing skill. International Journal of English Linguistics, 1(2), 299.

Pineteh, E. A. ( 2013). The Academic Writing Challenges of Undergraduate Students: A South African Case Study . International Journal of Higher Education, Vol. 3, No. 1.

Thaiss, C. a. (2006). Engaged Writers, Dynamic Disciplines: Research on the Academic Writing Life. Portsmouth, NH: Boynton/Cook, Heinnemann.

Zamel, V. (1983). The composing processes of advanced ESL students: six case studies. 